\title{
ELECTROSPRAY IONIZATION MASS SPECTROMETRY FRAGMENTATION PATHWAYS OF SALTS OF SOME 1,2,4-TRIAZOLYLTHIOACETATE ACIDS, THE ACTIVE PHARMACEUTICAL INGREDIENTS
}

\author{
VARYNSKYI BORYS ${ }^{1 *}$, KAPLAUSHENKO ANDRIY1 ${ }^{1}$, PARCHENKO VLADYMYR²
}

${ }^{1}$ Department of Physical and Colloidal Chemistry, Zaporozhye State Medical University, Pharmaceutical Faculty, Zaporozhye, Mayakowskyi Ave., 26, Ukraine. ${ }^{2}$ Department of Toxicologycal and Inorganic chemistry, Zaporozhye State Medical University, Pharmaceutical Faculty,

Zaporozhye, Mayakowskyi Ave., 26, Ukraine.

Email: varinsky@zsmu.zp.ua

Received: 12 December 2018, Revised and Accepted: 20 June 2018

\section{ABSTRACT}

Objective: The goal of this research was to study fragmentation pathways of series salts of 1,2,4-triazolylthioacetate acids.

Methods: The study was done in the Electrospray ionization source with single quadrupole mass spectrometer Agilent 6120 after elution through column Zorbax SB-C18, $30 \mathrm{~mm} \times 4.6 \mathrm{~mm}, 1.8 \mu \mathrm{m}$ at Agilent 1260 infinity high-performance liquid chromatography system. The series salts of 1,2,4-triazolylthioacetate acids were studied. These salts are active pharmaceutical ingredients of potential or registered pharmaceutical formulations.

Results: The mass spectra of corresponding compounds have analyzed. The fragmentation patterns of these compounds decay have proposed.

Conclusions: Studying the fragmentation of the indicated substances can be used for detecting the mentioned substances, as well as for confirming the structure of new compounds with the mass spectrum based on the patterns described above.

Keywords: Mass spectrometry, Electrospray ionization, High-performance liquid chromatography, Salts of the 1,2,4-triazolylthioacetate acids.

(C) 2018 The Authors. Published by Innovare Academic Sciences Pvt Ltd. This is an open access article under the CC BY license (http://creativecommons. org/licenses/by/4. 0/) DOI: http://dx.doi.org/10.22159/ajpcr.2018.v11i10.16564

\section{INTRODUCTION}

Derivatives of 1,2,4-triazoles are potential medicinal substances with diverse biological activity. They have antiviral, hepatoprotective, cardioprotective, immunomodulatory, interferonogenic, antioxidant, anti-inflammatory, neuroprotective, hepatoprotective, and other activities; moreover, some of them are already registered and used in the present-day veterinary (tryfusol and avesstim) and one of them are on the stage of registration for human use and manufacturing application (thiometrizol).

Development of methods for active pharmaceutical ingredients of 1,2,4-triazole derivatives determination in substances, pharmaceutical dosage forms, and biologic fluids is an important and urgent task.

The modern pharmaceutical analysis is characterized by prevailing of chromatographic methods, in particular, liquid chromatography (LC) with ultraviolet, diode array, and mass spectrometric detection.

Initially, chromatographic behavior [1] and behavior of substances in the ionic source [2] to optimize the conditions for defining data of active pharmaceutical ingredients were studied.

To describe the structure, identify, and quantify the substances with the help of high-performance LC-mass spectrometry (MS), it is necessary to know how compounds are fragmented in the ionic source.

There are many scientists that use mass spectrometric studies for confirmation of molecular mass and structure. For example, Philip et al. studied 1,2,4-triazole derivatives [3]

The electrospray LC-mass spectrometry (ESI-LC-MS) testing of the synthesized compounds confirmed the formation of the novel bis 1,2,4-triazoles [4] 1,2,4-triazoles were studied in the research of Kaplaushenko et al. [5].

There are works that study patterns of mass spectrometric decompositions of 1,2,4-triazole derivatives. Thus, for example, the Salgın-Gökșen et al. offered the fragmentation patterns of 1,2,4-triazole5(4)-thiones series. It describes both the release of a substitute radical in a triazole cycle and partial disintegration of substituents [6].

The article İl, Küçükgüzel et al. showed fragmentation patterns including partial destruction of triazole cycles with the formation of tripartite diazo heterocyclic radical cations [7]

Similar structures are also described in the research Gülerman et al. [8].

Alternative options for decomposition of 1,2,4-triazole derivatives are offered by the authors of Eswaran et al. [9].

Possible variants of decomposition of 1,2,4-triazoles are also discussed in the article [10]

The goal of our research was to study the mass spectrum resulted from ESI in the area of collision induced dissociation by a single quadrupole mass spectrometer and offers fragmentation patterns of series of active pharmaceutical ingredients, derivatives, 1,2,3-triazole-ylthio-acetate acids in case of two different voltages during fragmentation, i.e. 100 and $200 \mathrm{~V}$.

\section{MATERIALS AND METHODS}

Device LC MS

High performance LC (HPLC) system Agilent 1260 Infinity (degasser, binary pump, autosampler, quadrupole mass spectrometer detector Agilent 6120 with ESI). 
Table 1: ESI-MS conditions

\begin{tabular}{llll}
\hline Compound & {$[\mathbf{M H}]+\mathbf{m} / \mathbf{z}$} & Drying gas temperature, T & Nebulizer pressure, psig \\
\hline 1 & 343 & 300 & 53 \\
2 & 302 & 247 & 46 \\
3 & 237 & 300 & 50 \\
4 & 335 & 300 & 52 \\
5 & 273 & 228 & 57 \\
6 & 287 & 300 & 10 \\
7 & 266 & 300 & 60 \\
\hline
\end{tabular}

ESI-MS: Electrospray ionization mass spectrometry

\section{Compounds}

There were used substances, which were synthesized in Zaporozhye State Medical University at the toxicological and inorganic chemistry department, physical and colloid chemistry department. The composition of compounds was proved by elemental analysis and infrared, ultraviolet (UV), 1H-NMR spectroscopy, and chromatography with mass spectrometric detection:

1. Morpholin-4-ium 2-((4-(2-methoxyphenyl)-5-(pyridin-4-yl)-4H1,2,4-triazol-3-yl)thio)acetate;

2. Piperidin-1-ium 2-((5-(furan-2-yl)-4-phenyl-4H-1,2,4-triazol-3-yl) thio)acetate;

3. Morpholin-4-ium 2-((5-(pyridin-4-yl)-4H-1,2,4-triazol-3-yl)thio) acetate;

4. Morpholin-4-ium 2-((5-(morpholinomethyl)-4-phenyl-4H-1,2,4triazol-3-yl)thio)acetate;

5. Morpholin-4-ium 2-((4-ethyl-5-(morpholinomethyl)-4H-1,2,4triazol-3-yl)thio)acetate;

6. Morpholin-4-ium 2-((4-methyl-5-(morpholinomethyl)-4H-1,2,4triazol-3-yl)thio)acetate;

7. Zinc 2-((5-(2-methoxyphenyl)-4H-1,2,4-triazol-3-yl)thio)acetate.

Acetonitrile HPLC gradient grade from Merck KGaA (Darmstadt, Germany), formic acid (100\%) from Merck KGaA (Darmstadt, Germany). Highly purified water $\left(18 \mathrm{M} \Omega\right.$ under $\left.25^{\circ} \mathrm{C}\right)$ was produced with the usage of the system Direct Q 3UV Millipore (Molsheim, France).

\section{Sample solutions}

Solutions of compounds 1-6 were prepared by dissolving in $50 \%$ acetonitrile, compound 7 in dimethyl sulfoxide to a final the concentration of $1 \mathrm{mg} / \mathrm{mL}$.

\section{Software}

The package OpenLAB CDS software was used for acquisition. The Software packages ChemSketch ACDlabs 12.0, ChemBioOffice 2012 were used for demonstration of the fragmentation patterns.

\section{HPLC-MS conditions}

The chromatography separation was done in isocratic mode at flow rate $0.4 \mathrm{~mL} / \mathrm{min}$. The eluent consist on the water and acetonitrile (50:50) with $0.1 \%$ of methanoic acid. Column was Zorbax SB-C18, $30 \mathrm{~mm} \times 4.6 \mathrm{~mm}$, $1.8 \mu \mathrm{m}$. Column temperature was $40^{\circ}$. The ion source was atmospheric pressure ionization (API)-ES. The mass spectrometric detection was dine at positive polarity. The drying gas rate (nitrogen) was $10 \mathrm{~L} /$ min. The capillary voltage of ESI was $4000 \mathrm{~B}$. The mass spectrometric detection was done in SCAN mode at $\mathrm{m} / \mathrm{z}$ range 100-1000.

ESI-MS conditions have proposed earlier showed in Table 1 [2].

\section{RESULTS AND DISCUSSION}

The mass spectra were presented in graphical and tabular form, with the providing of the most intensive peaks starting about $1 \%$. The maximal peak from isotope pattern peaks was shown. We have analyzed the mass spectra and suggested possible fragmentation pathways of the compounds.
Table 2: The values of ions' $\mathrm{m} / \mathrm{z}$ of morpholin-4-ium

2-((4-(2-methoxyphenyl)-5-(pyridin-4-yl)-

4H-1,2,4-triazol-3-yl) thio) acetate ions and relative abundance at $100 \mathrm{~V}$ and $200 \mathrm{~V}$

\begin{tabular}{|c|c|c|c|}
\hline \multicolumn{2}{|l|}{$100 \mathrm{~V}$} & \multicolumn{2}{|l|}{$200 \mathrm{~V}$} \\
\hline $\mathbf{m} / \mathbf{z}$ & Abundance, $\%$ & $\mathbf{m} / \mathbf{z}$ & Abundance, $\%$ \\
\hline 299.10 & 2.8 & 105.10 & 34.7 \\
\hline 313.00 & 2.6 & 119.10 & 2.7 \\
\hline 343.00 & 100.0 & 132.10 & 9.7 \\
\hline 344.10 & 19.0 & 149.10 & 1.6 \\
\hline 357.00 & 3.7 & 178.00 & 1.7 \\
\hline \multirow[t]{15}{*}{358.00} & 1.0 & 195.00 & 1.0 \\
\hline & & 211.00 & 1.4 \\
\hline & & 223.10 & 4.5 \\
\hline & & 237.10 & 1.3 \\
\hline & & 251.10 & 12.6 \\
\hline & & 265.00 & 1.4 \\
\hline & & 269.10 & 2.2 \\
\hline & & 283.00 & 2.1 \\
\hline & & 285.00 & 11.3 \\
\hline & & 297.00 & 1.0 \\
\hline & & 299.10 & 9.5 \\
\hline & & 343.00 & 100.0 \\
\hline & & 357.00 & 4.4 \\
\hline & & 363.00 & 1.0 \\
\hline & & 365.00 & 3.5 \\
\hline
\end{tabular}

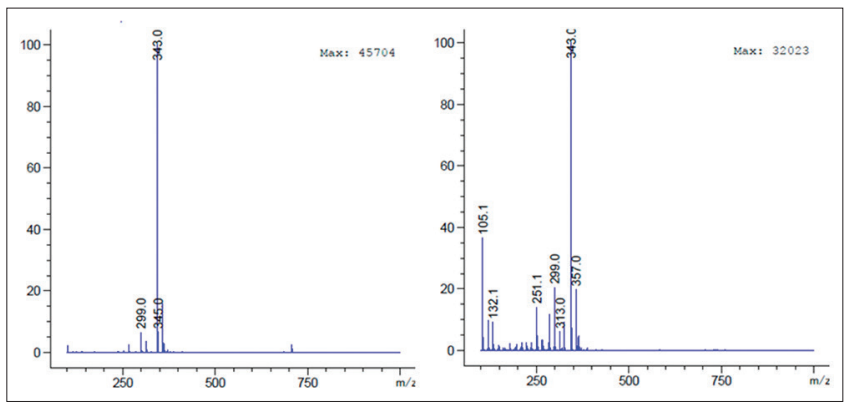

Fig. 1: Mass spectra of the morpholin-4-ium

2-((4-(2-methoxyphenyl)-5-(pyridin-4-yl)-4H-1,2,4-triazol-3-yl) thio)acetate at 100 and $200 \mathrm{~V}$

Morpholin-4-ium 2-((4-(2-methoxyphenyl)-5-(pyridin-4-yl)-4H1,2,4-triazol-3-yl)thio)acetate

There are mass spectra at Fig. 1 and Table 2.

In the acidic medium of an eluent, the salt form of the active pharmaceutical ingredient turns into acid form which was protonated on triazole nitrogen and forms a quasimolecular cation with $\mathrm{m} / \mathrm{z}$ 343 (Fig. 2). Cations with $\mathrm{m} / \mathrm{z} 313$ appear with the release of the oxymethyl group and 299 with the release of carbon oxide (IV) from a quasimolecular cation in case of both $100 \mathrm{~V}$ and $200 \mathrm{~V}$. When the bond between sulfur and carbon of the triazole cycle was broken at $200 \mathrm{~V}$, the cation with $\mathrm{m} / \mathrm{z} 251$ was formed. With further release of oxymethyl 
fragment, the cation with $\mathrm{m} / \mathrm{z} 223$ was formed. A separation of the hydrazine fragment from the triazole cycle was caused the cation with $\mathrm{m} / \mathrm{z} 197$ formation. The cation with $\mathrm{m} / \mathrm{z} 105$ after the release of the pyridinic cycle and methylene group appears. Another cation (m/z 105) may was appeared with the release of the benzene cycle and methylene group. Two cations (m/z 149 and 132) were formed after the release of a thioacetate fragment linked with the residues of the triazole cycle.

Piperidin-1-ium 2-((5-(furan-2-yl)-4-phenyl-4H-1,2,4-triazol-3yl)thio)acetate

The fragmentation of this compound described on the base of the mass spectra presented at Fig. 3 and Table 3.

The peak of the quasimolecular ion of an acid form protonated on triazole nitrogen was seen at both $100 \mathrm{~V}$ and $200 \mathrm{~V}$ and has $\mathrm{m} / \mathrm{z} 302$ (Figs. 4 and 5).

The peak of protonated piperidine salt with $\mathrm{m} / \mathrm{z} 387$ was detected at $100 \mathrm{~V}$. The peak of the dimer ion with $\mathrm{m} / \mathrm{z} 603$ was detected in the mass spectrum at the $100 \mathrm{~V}$. The cation with $\mathrm{m} / \mathrm{z} 284$ was formed at the release of the $\mathrm{OH}$-group from the quasimolecular ion of the acid form of the active pharmaceutical ingredient. The cation with $\mathrm{m} / \mathrm{z} 256$ at the further separation of the $\mathrm{CO}$-fragment occurs. Two variants of the cation with $\mathrm{m} / \mathrm{z} 242$ at further release of the methylene group and cyclization were formed. The cation with $\mathrm{m} / \mathrm{z} 214$ at the separation of sulfur and partial reduction of the triazole cycle was formed. With partial disintegration of the triazole cycle, the cation with $\mathrm{m} / \mathrm{z} 189$

Table 3: The values of ions $\mathrm{m} / \mathrm{z}$ of the piperidin-1-ium 2-((5-(furan-2-yl)-4-phenyl-4H-1,2,4-triazol-3-yl) thio) acetate and relative abundance at $100 \mathrm{~V}$ and $200 \mathrm{~V}$

\begin{tabular}{lllll}
\hline $\mathbf{1 0 0} \mathbf{~ V}$ & & & $\mathbf{2 0 0} \mathbf{~ V}$ & \\
\cline { 1 - 1 } $\mathbf{m} / \mathbf{z}$ & Abundance, $\mathbf{0}$ & & $\mathbf{m} / \mathbf{z}$ & Abundance, \% \\
\hline 302.00 & 100.0 & 105.10 & 3.4 \\
304.00 & 6.8 & 121.10 & 8.0 \\
387.10 & 3.3 & 149.00 & 5.0 \\
603.00 & 27.1 & 170.10 & 7.7 \\
& & 189.00 & 4.9 \\
& & 214.00 & 1.2 \\
& & 242.00 & 11.9 \\
& & 256.00 & 1.3 \\
& & 284.00 & 7.7 \\
& & 302.00 & 100.0 \\
\hline
\end{tabular}

Table 4: The values of ions $\mathrm{m} / \mathrm{z}$ of the morpholin-4-ium 2-((5-(pyridin-4-yl)-4H-1,2,4-triazol-3-yl) thio) acetate and relative abundance at $100 \mathrm{~V}$ and $200 \mathrm{~V}$

\begin{tabular}{lllll}
\hline $\mathbf{1 0 0} \mathbf{~ V}$ & & & $\mathbf{2 0 0} \mathbf{~ V}$ & \\
\cline { 1 - 2 } $\mathbf{m} / \mathbf{z}$ & Abundance, $\mathbf{0}$ & & $\mathbf{m} / \mathbf{z}$ & Abundance, \% \\
\hline 102.20 & 2.6 & & 103.00 & 1.7 \\
134.00 & 1.2 & 105.10 & 100.0 \\
193.00 & 3.1 & 118.10 & 3.8 \\
237.00 & 100.0 & 123.00 & 4.6 \\
& & 149.00 & 1.7 \\
& & 150.00 & 16.6 \\
& & 178.00 & 10.2 \\
& & 191.00 & 4.4 \\
& & 193.00 & 1.8 \\
& & 219.00 & 6.0 \\
& & 237.00 & 24.2 \\
& & 238.00 & 3.0 \\
& & 239.00 & 1.6 \\
& & 274.80 & 1.5 \\
& & 510.90 & 1.2 \\
& & 532.90 & 1.0 \\
\hline
\end{tabular}

occurs and it turns into the cation with m/z 170 with further release of ammonia. With destruction of the furan ring and partial decomposition of the triazole cycle, cations with m/z 149 and 121 sequentially occur.

Morpholin-4-ium 2-((5-(pyridin-4-yl)-4H-1,2,4-triazol-3-yl)thio) acetate

According to mass spectra (Fig. 6 and Table 4) in the acidic medium of the eluent, morpholinium salt turns into the corresponding acid, which forms the cation with $\mathrm{m} / \mathrm{z} 237$ when linked with a proton of hydrogen.

At $100 \mathrm{~V}$, release of carbon oxide (IV) leads to the occurrence of the positive ion with m/z 193 (Fig. 7).

Separation of the pyridinic cycle and methyl group results in the formation of the cation with $\mathrm{m} / \mathrm{z} 102$, while partial destruction of

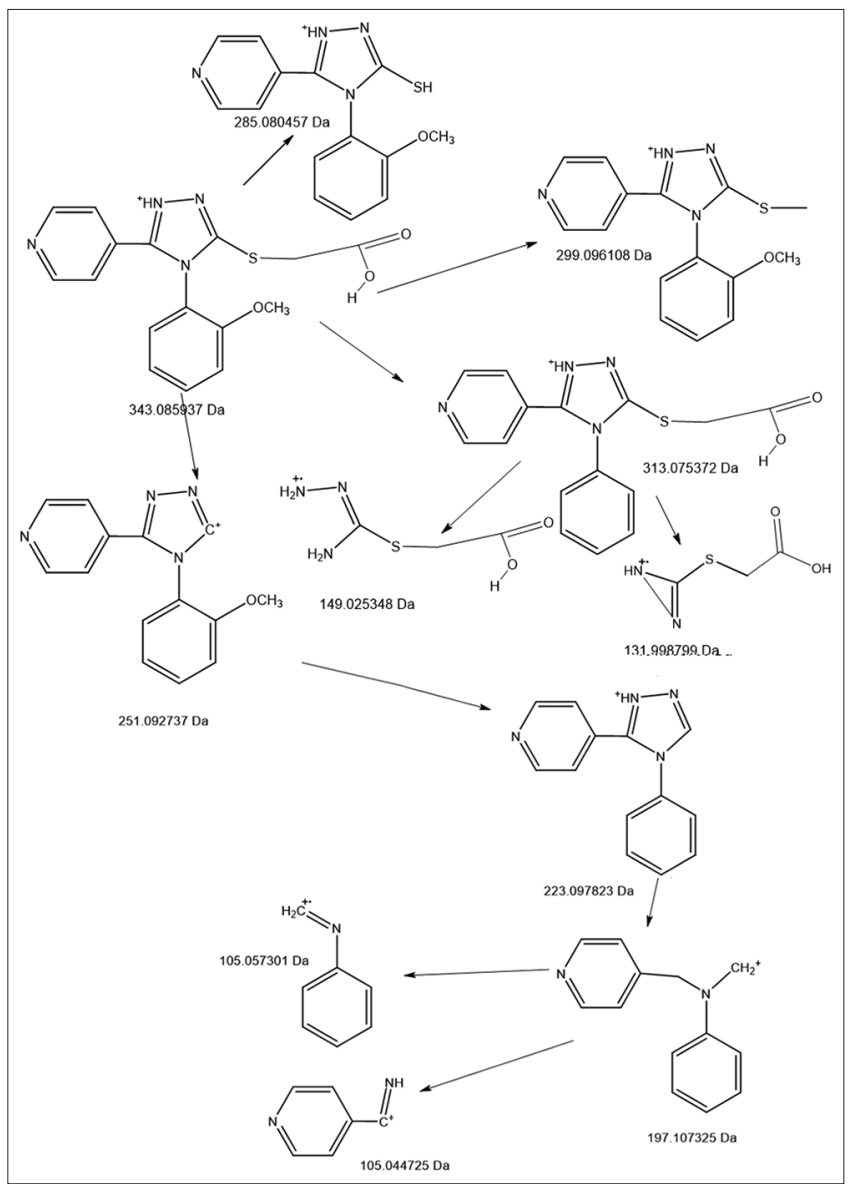

Fig. 2: Proposed fragmentation pattern of the morpholin-4-ium 2-((4-(2-methoxyphenyl)-5-(pyridin-4-yl)-4H-1,2,4-triazol-3-yl) thio)acetate at $200 \mathrm{~V}$

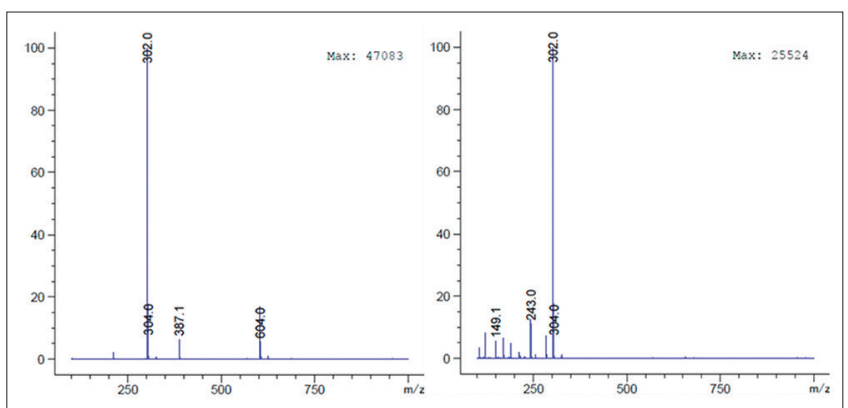

Fig. 3: Mass spectra of the piperidin-1-ium 2-((5-(furan-2-yl)-4phenyl-4H-1,2,4-triazol-3-yl)thio)acetate at 100 and $200 \mathrm{~V}$ 


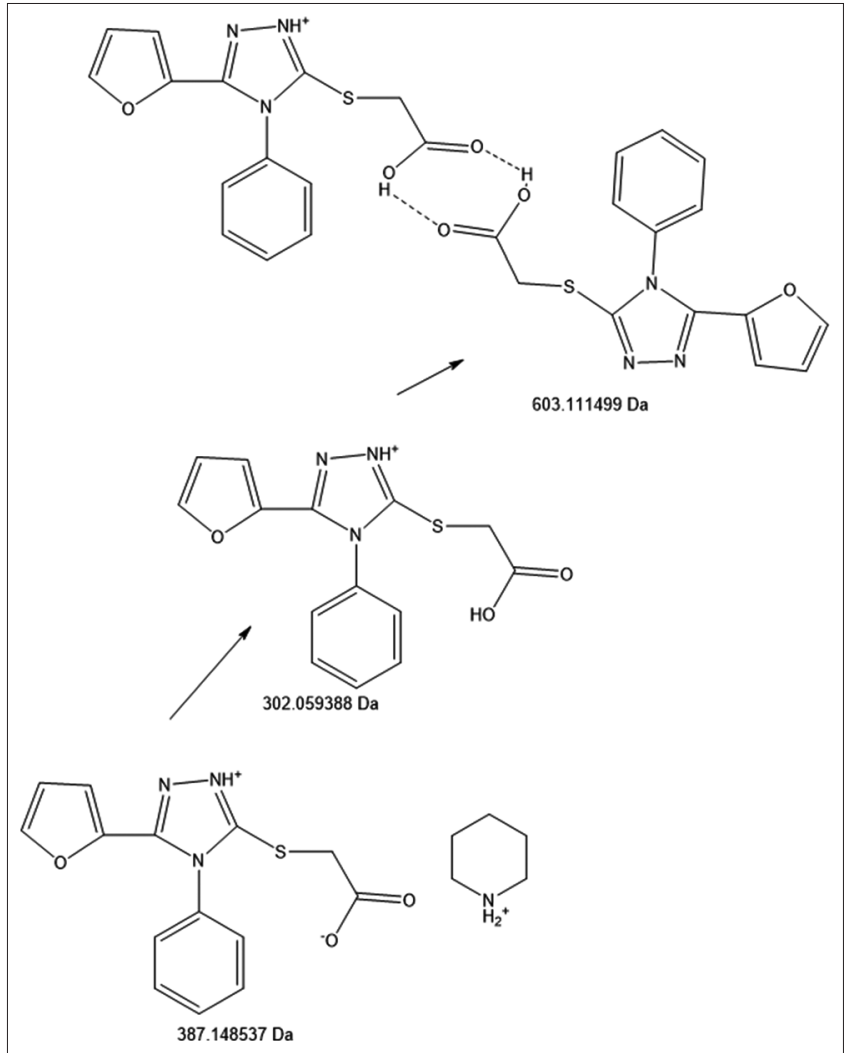

Fig. 4: Proposed fragmentation pattern of the piperidin-1-ium 2-((5-(furan-2-yl)-4-phenyl-4H-1,2,4-triazol-3-yl)thio)acetate at $100 \mathrm{~V}$

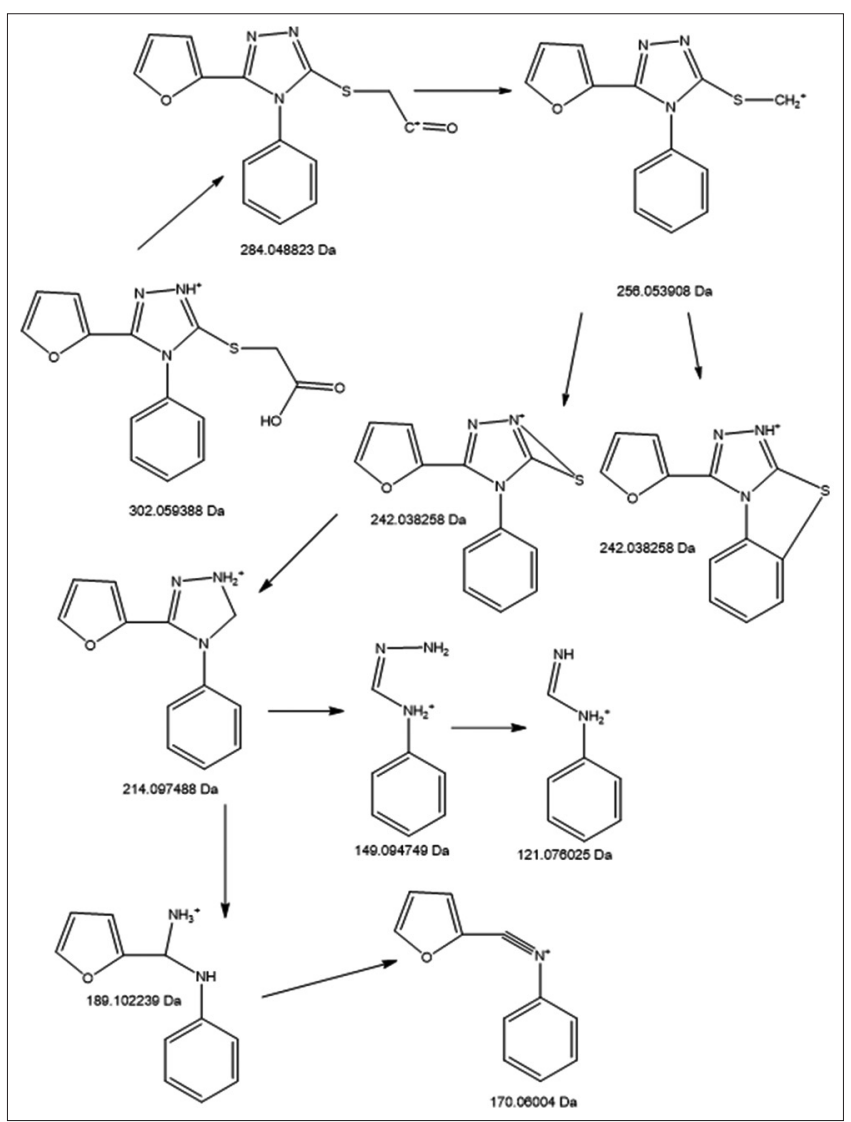

Fig. 5: Proposed pathways for the dissociation of piperidin-1-ium 2-((5-(furan-2-yl)-4-phenyl-4H-1,2,4-triazol-3-yl)thio)acetate and theoretical monoisotopic masses of ions at $200 \mathrm{~V}$

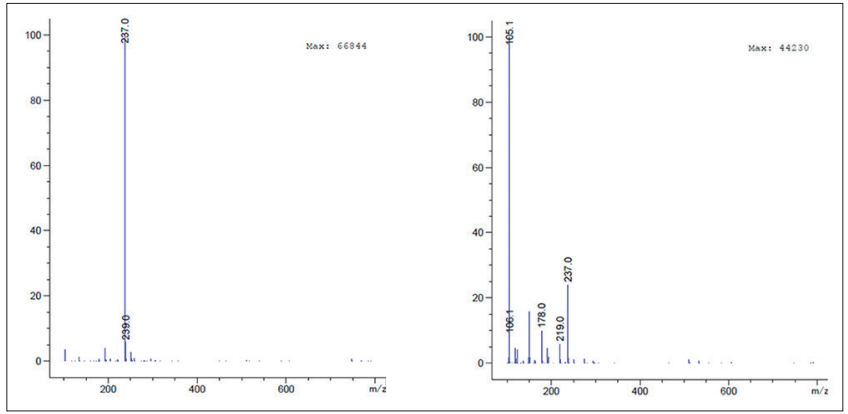

Fig. 6: Mass spectra of morpholin-4-ium 2-((5-(pyridin-4-yl)-4H1,2,4-triazol-3-yl)thio)acetate at 100 and $200 \mathrm{~V}$

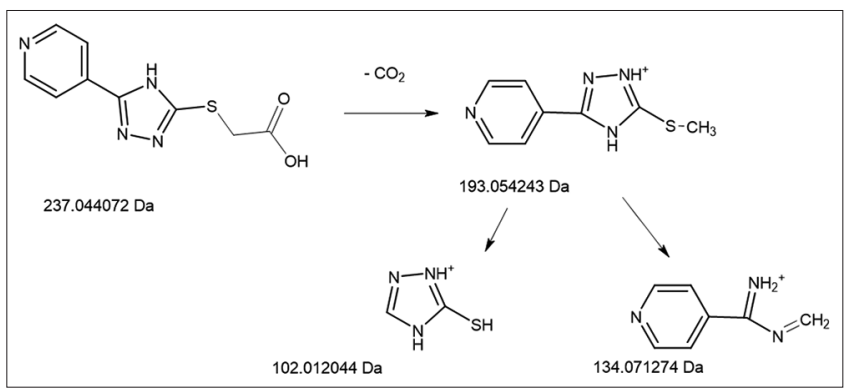

Fig. 7: Proposed fragmentation pattern of the morpholin-4-ium 2-((5-(pyridin-4-yl)-4H-1,2,4-triazol-3-yl)thio)acetate at $100 \mathrm{~V}$

Table 5: The values of ions $\mathrm{m} / \mathrm{z}$ of the morpholin-4-ium

2-((5-(morpholinomethyl)-4-phenyl-4H-1,2,4-triazol-3-yl)

thio) acetate and relative abundance at $100 \mathrm{~V}$ and $200 \mathrm{~V}$

\begin{tabular}{|c|c|c|c|}
\hline \multicolumn{2}{|l|}{$100 \mathrm{~V}$} & \multicolumn{2}{|l|}{$200 \mathrm{~V}$} \\
\hline $\mathbf{m} / \mathbf{z}$ & Abundance, \% & $\mathbf{m} / \mathbf{z}$ & Abundance, $\%$ \\
\hline 335.10 & 100.0 & 100.10 & 100.0 \\
\hline 669.10 & 5.9 & 101.10 & 6.0 \\
\hline 670.10 & 2.1 & 105.10 & 2.0 \\
\hline \multirow[t]{14}{*}{707.10} & 3.1 & 117.10 & 1.5 \\
\hline & & 131.00 & 3.3 \\
\hline & & 148.10 & 7.1 \\
\hline & & 173.00 & 1.7 \\
\hline & & 174.00 & 1.7 \\
\hline & & 188.90 & 3.0 \\
\hline & & 190.00 & 1.2 \\
\hline & & 202.10 & 3.2 \\
\hline & & 230.10 & 2.1 \\
\hline & & 236.00 & 2.0 \\
\hline & & 248.00 & 5.7 \\
\hline & & 335.10 & 25.1 \\
\hline & & 357.10 & 3.4 \\
\hline & & 373.00 & 3.4 \\
\hline
\end{tabular}

the triazole cycle creates the cation with $\mathrm{m} / \mathrm{z}$ 134. The formation of cation with $\mathrm{m} / \mathrm{z} 219$ was occured by elemination of the $\mathrm{OH}$ group from quasimolecular ion at $200 \mathrm{~V}$ (Fig. 8).

On subsequent CO cleavage, cation with $\mathrm{m} / \mathrm{z} 193$ was appeared. It creates cation with $\mathrm{m} / \mathrm{z} 191$ in the subsequent dehydrogenation. The cation with $\mathrm{m} / \mathrm{z} 118$ was formed at isolation of the pyridine moiety. This cation may also form a cation radical with $\mathrm{m} / \mathrm{z}$ 119. Then, cation radicals with m/z 103 and 105 after isolation methyl group appeared. Removal of the methylene group from the cation with m/z 191 leads to the formation of a cation with $\mathrm{m} / \mathrm{z}$ 179. Further, the cation radical with $\mathrm{m} / \mathrm{z} 178$ was formed, which may be having two resonance forms. Next, release of the $\mathrm{SH}$ and complete or partial reduction of the triazole cycle 
forms cation radical with m/z 150 and m/z 149, respectively. Further, partial destruction of the triazole cycle leads to the cation radical with $\mathrm{m} / \mathrm{z}$ 123. Removal of the pyridine cycle from the cation with $\mathrm{m} / \mathrm{z} 191$ and partial and complete reduction of the triazole cycle leads to the formation of a two cations with $\mathrm{m} / \mathrm{z} 118$ and 119. Next, release of the methyl group forms cations with m/z 103 and 105, respectively.

Morpholin-4-ium 2-((5-(morpholinomethyl)-4-phenyl-4H-1,2,4triazol-3-yl)thio)acetate

The mass spectra are shown in Fig. 9 and Table 5.

At $100 \mathrm{~V}$, the peak of the quasimolecular ion of the protonated acid form of the active pharmaceutical ingredient with $\mathrm{m} / \mathrm{z} 335$ was observed (Fig. 10). Besides, there was an ion with $\mathrm{m} / \mathrm{z}$ equal 669 which was dimer. At addition to it of the potassium ion, the ion with $\mathrm{m} / \mathrm{z}=707$ occurs.

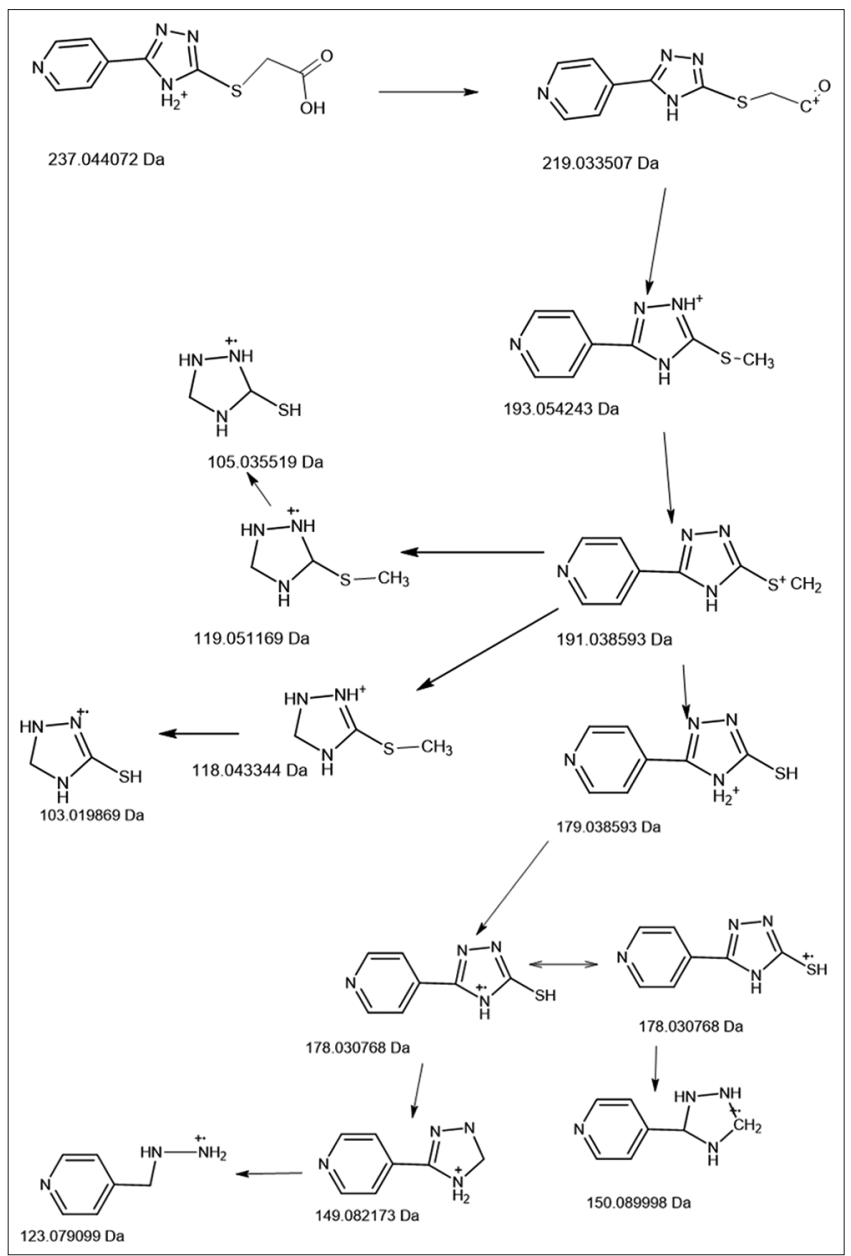

Fig. 8: Proposed fragmentation pattern of the morpholin-4-ium 2-((5-(pyridin-4-yl)-4H-1,2,4-triazol-3-yl)thio)acetate at $200 \mathrm{~V}$
At $200 \mathrm{~V}$, ions with $\mathrm{m} / \mathrm{z}=357$ and 373 in the mass spectrum were observed, they correspond an adduct of the acid form of the substance with cations of sodium $[\mathrm{M}+\mathrm{Na}]^{+}$and potassium $[\mathrm{M}$ $+\mathrm{K}^{+}$, respectively (Fig. 11). Separation of the morpholine cycle from the quasimolecular ion results in the formation of the cation with $\mathrm{m} / \mathrm{z}$ 236. With further release of the carbon oxide (IV) and further cyclization, the cation radical with $\mathrm{m} / \mathrm{z} 189$ was formed. With the release of the phenyl fragment and partial destruction of the morpholine fragment, the cation with $\mathrm{m} / \mathrm{z} 173$ results from the quasimolecular cation was formed. With further release of the acetate fragment, the cation with $\mathrm{m} / \mathrm{z}=131$ appears. The cation radical ion with $\mathrm{m} / \mathrm{z}=248$ occurs from the quasimolecular ion when the link between sulfur and carbon of 1,2,4-triazole was broken, as well as with the reduction of the triazole cycle. With further release of the methylene group and oxygen of the morpholine cycle, the radical cation with $\mathrm{m} / \mathrm{z} 202$ appears, while with destruction of 1,2,4-triazole cycle the morpholine-methylene cation with $\mathrm{m} / \mathrm{z}=100$ may was formed. With the release of the methylene-morpholine fragment, the cation with $\mathrm{m} / \mathrm{z}=117$ was formed. With further release of the methyl group and reduction of the triazole cycle, the cation with $\mathrm{m} / \mathrm{z}=105$ was formed.

Morpholin-4-ium 2-((4-ethyl-5-(morpholinomethyl)-4H-1,2,4triazol-3-yl)thio)acetate

The mass spectra are presented in Fig. 12 and Table 6.

At $100 \mathrm{~V}$, the peak of the quasimolecular ion of the acid form of the active pharmaceutical ingredient with $\mathrm{m} / \mathrm{z} 287$ was observed (Fig. 13). Furthermore, a dimer ion with $\mathrm{m} / \mathrm{z} 573$ as well as adducts of the dimer ion with sodium $(\mathrm{M} / \mathrm{z}=595)$ and potassium $(\mathrm{m} / \mathrm{z}=611)$ were observed.

A quasimolecular ion was present at $200 \mathrm{~V}$. Ions with m/z 309 and 325 were observed, which corresponds, respectively, to the adducts of the acid form with the ion of sodium $[\mathrm{M}+\mathrm{Na}]^{+}$and potassium $[\mathrm{M}+\mathrm{K}]^{+}$ (Fig. 14). With destruction of 1,2,4-triazole cycle of the quasimolecular ion, the methylene-morpholine cation with $\mathrm{m} / \mathrm{z}=100$ was formed. The

Table 6: The values of ions $\mathrm{m} / \mathrm{z}$ of morpholin-4-ium

2-((4-ethyl-5-(morpholinomethyl)-4H-1,2,4-triazol-3-yhe l) thio) acetate and relative abundance at $100 \mathrm{~V}$ and $200 \mathrm{~V}$

\begin{tabular}{llll}
\hline $\mathbf{1 0 0 ~ V}$ & & $\mathbf{2 0 0} \mathbf{~ V}$ & \\
\hline $\mathbf{m} / \mathbf{z}$ & $\begin{array}{l}\text { Abundance, } \% \\
\text { undance, \% }\end{array}$ & $\mathbf{m} / \mathbf{z}$ & $\begin{array}{l}\text { Abundance, } \\
\mathbf{\%}\end{array}$ \\
\hline 100.10 & 3.6 & 100.10 & 100.0 \\
287.00 & 100.0 & 101.00 & 6.0 \\
573.20 & 1.4 & 170.00 & 2.3 \\
595.10 & 1.5 & 188.00 & 2.1 \\
611.10 & 1.2 & 199.90 & 1.7 \\
& & 287.00 & 11.1 \\
& & 309.00 & 7.6 \\
& & 325.00 & 0.9 \\
\hline
\end{tabular}
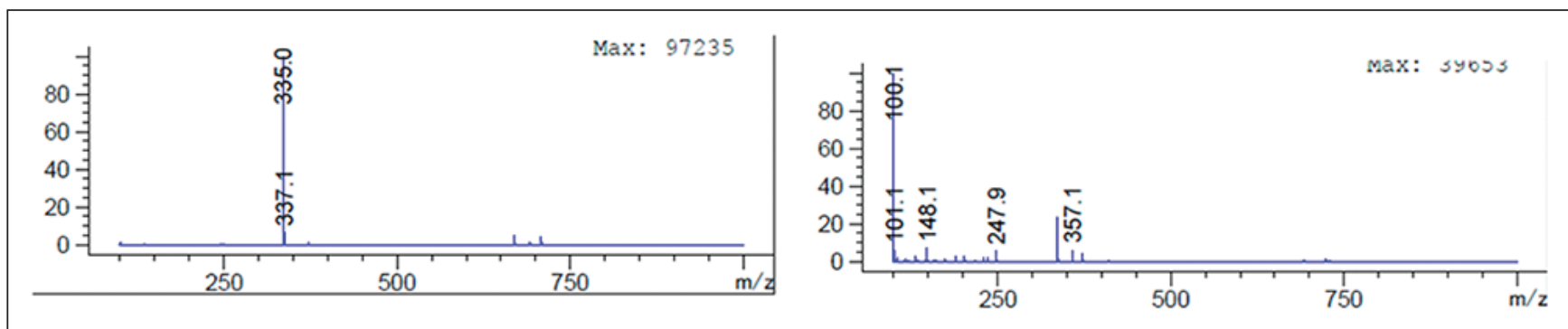

Fig. 9: Mass spectra of morpholin-4-ium 2-((5-(morpholinomethyl)-4-phenyl-4H-1,2,4-triazol-3-yl)thio)acetate at 100 and $200 \mathrm{~V}$ 
separation of the morpholine fragment from the quasimolecular ion, the cation with $\mathrm{m} / \mathrm{z}=200$ was formed. With further separation of the methylene group, we observed the ion with $\mathrm{m} / \mathrm{z}=188$. Separation of $\mathrm{OH}$-group results in occurrence of the cation with $\mathrm{m} / \mathrm{z}=170$. The cation

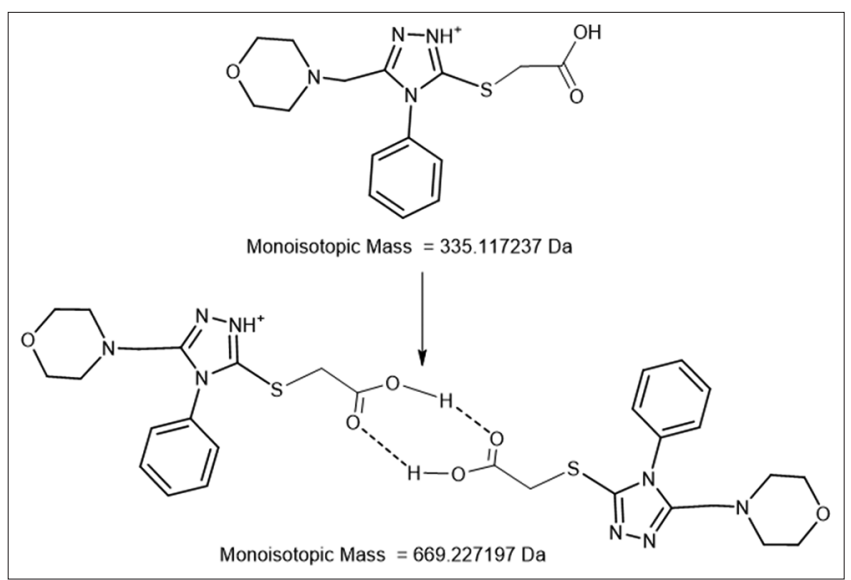

Fig. 10: Proposed fragmentation pattern of the morpholin-4-ium 2-((5-(morpholinomethyl)-4-phenyl-4H-1,2,4-triazol-3-yl)thio) acetate at $100 \mathrm{~V}$ with $\mathrm{m} / \mathrm{z}=142$ at the loss of $\mathrm{CO}$ appeared. Next, release of the ethyl group results the ion with $\mathrm{m} / \mathrm{z}=114$.

Morpholin-4-ium 2-((4-methyl-5-(morpholinomethyl)-4H-1,2,4triazol-3-yl)thio)acetate

The mass spectrum of this substance under the voltage of $100 \mathrm{~V}$ (Fig. 15 and Table 7) of the fragmentor showed the peak of the quasimolecular ion of the acid form with $\mathrm{m} / \mathrm{z}=273$, as well as the adduct of the potassium cation $\left([\mathrm{M}+\mathrm{K}]^{+}\right) \mathrm{m} / \mathrm{z}=311$, dimer cation $\left([2 \mathrm{M}]^{+}\right)$with $\mathrm{m} /$ $\mathrm{z}=545$, and dimeric adduct with potassium cation $\mathrm{m} / \mathrm{z}=583\left([2 \mathrm{M}+\mathrm{K}]^{+}\right)$.

Table 7: The values of ions $\mathrm{m} / \mathrm{z}$ of morpholin-4-ium 2-((4-methyl-5-(morpholinomethyl)-4H-1,2,4-triazol-3-yl) thio) acetate abundance at $100 \mathrm{~V}$ and $200 \mathrm{~V}$

\begin{tabular}{lllll}
\hline $\mathbf{1 0 0} \mathbf{~ V}$ & & \multicolumn{2}{c}{$\mathbf{2 0 0} \mathbf{~ V}$} & \\
\cline { 1 - 1 } $\mathbf{m} / \mathbf{z}$ & $\begin{array}{l}\text { Abundance, } \\
\text { \% }\end{array}$ & & $\mathbf{m} / \mathbf{z}$ & Abundance, \% \\
& & & \\
\hline 100.20 & 2.3 & 100.20 & 100.0 \\
273.10 & 100.0 & 174.10 & 1.3 \\
311.00 & 9.9 & 186.10 & 1.9 \\
545.10 & 19.1 & 273.10 & 17.9 \\
583.10 & 2.5 & & \\
\hline
\end{tabular}

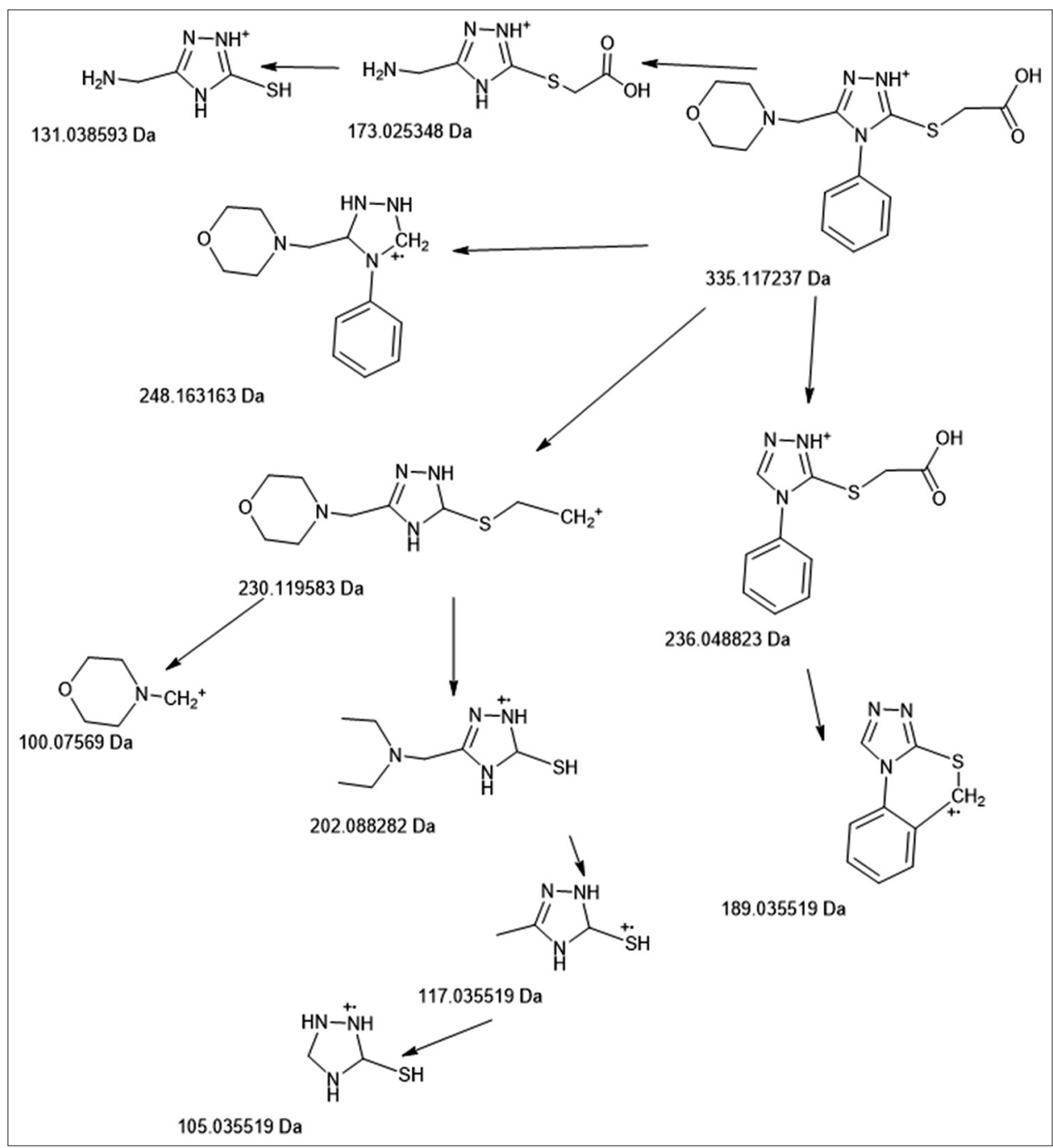

Fig. 11: Proposed fragmentation pattern of the morpholin-4-ium 2-((5-(morpholinomethyl)-4-phenyl-4H-1,2,4-triazol-3-yl)thio)acetate at $200 \mathrm{~V}$ 


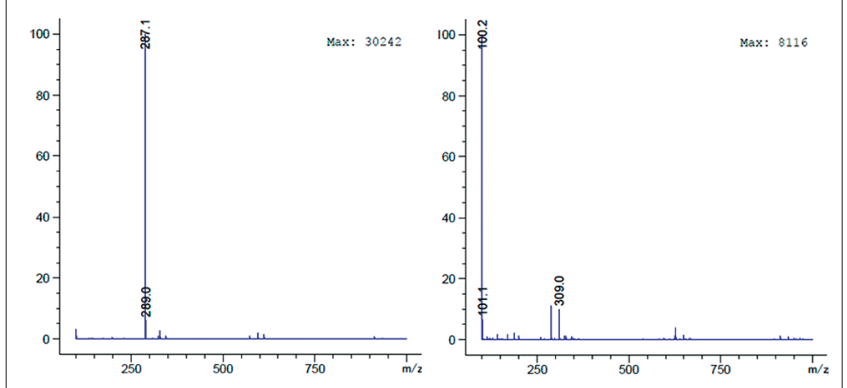

Fig. 12: Mass spectra of morpholin-4-ium 2-((4-ethyl-5(morpholinomethyl)-4H-1,2,4-triazol-3-yhe l)thio)acetate at different fragmentor voltage $(100$ and $200 \mathrm{~V})$

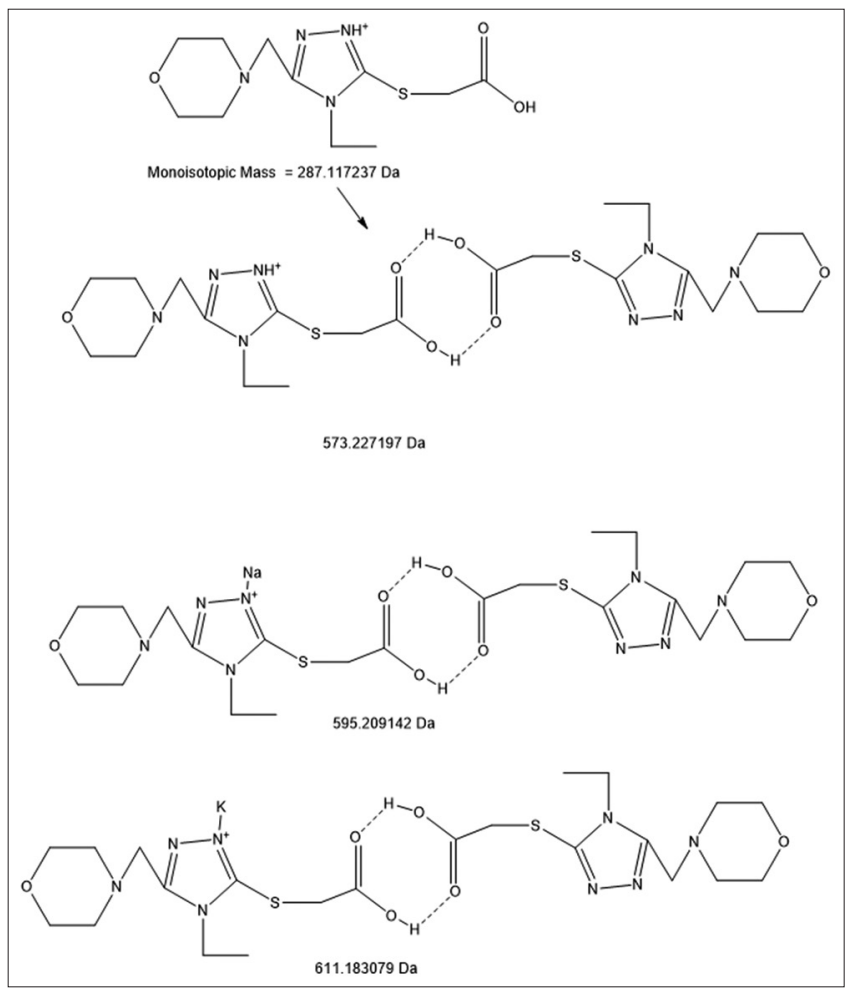

Fig. 13: Proposed fragmentation pattern of the morpholin-4-ium 2-((4-ethyl-5-(morpholinomethyl)-4H-1,2,4-triazol-3-yl)thio) acetate at $100 \mathrm{~V}$

Adducts with sodium ions were also observed, but their intensity was $<1.0$. With fragmentation of the quasimolecular ion, the morpholinemethylene cation with $\mathrm{m} / \mathrm{z}=100$ was formed (Fig. 16).

Under the voltage of $200 \mathrm{~V}$ (Fig. 17) of the fragmentor, the quasimolecular ion of the acid form of the substance was observed which forms the morpholine-methylene cation with $\mathrm{m} / \mathrm{z}=100$ with cleavage of the 1,2,4-triazole cycle. Release of the morpholine fragment results in the formation of the cation with $\mathrm{m} / \mathrm{z}=186$. Then, the methylene group was separated and the cation with $\mathrm{m} / \mathrm{z}=174$ was formed.

Zinc 2-((5-(2-methoxyphenyl)-4H-1,2,4-triazol-3-yl)thio)acetate There were mass spectra of this compound at Fig. 18 and Table 8.

At the voltage of $100 \mathrm{~V}$, the cation with $\mathrm{m} / \mathrm{z}=266$ was observed that corresponds to the quasimolecular ion of the acid form of the active pharmaceutical ingredient (Fig. 19). On addition of the sodium cation, the adduct with $\mathrm{m} / \mathrm{z}=288\left([\mathrm{M}+\mathrm{Na}]^{+}\right)$was formed. With separation of carbon oxide (IV), the cation with $\mathrm{m} / \mathrm{z}=220$ appeared.

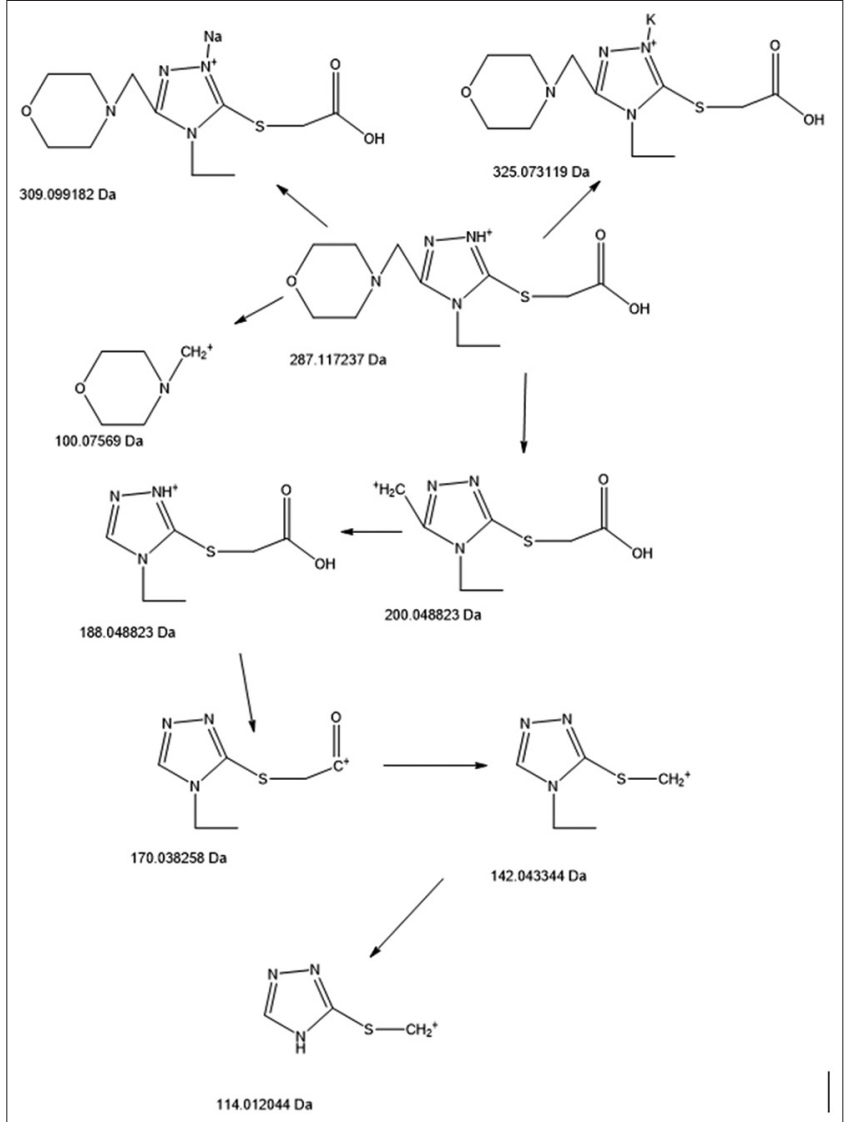

Fig. 14: Proposed fragmentation pattern of the morpholin morpholin-4-ium 2-((4-ethyl-5-(morpholinomethyl)-4H-1,2,4triazol-3-yhe l)thio)acetate at $200 \mathrm{~V}$

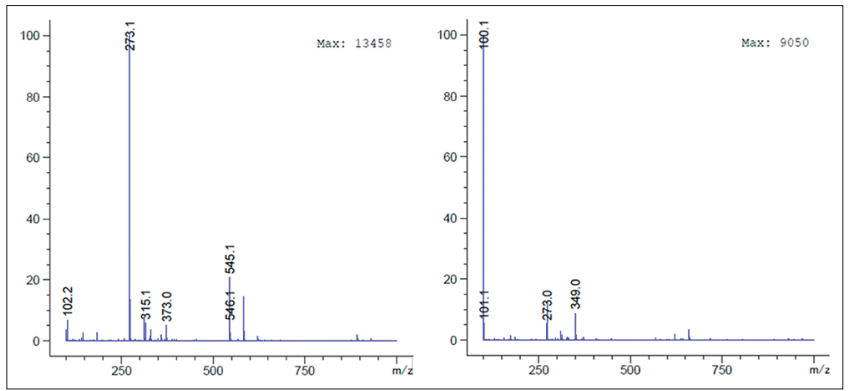

Fig. 15: Mass spectra of morpholin-4-ium 2-((4-methyl-5(morpholinomethyl)-4H-1,2,4-triazol-3-yl)thio)acetate at different fragmentor voltage $(100$ and $200 \mathrm{~V})$

The same cations were observed at the voltage of $200 \mathrm{~V}$ of the fragmentor (Fig. 20). Besides, with fragmentation of the quasimolecular ion with the release of the thioacetate group from the triazole fragment and methyl radical from the methoxy group, the radical cation with $\mathrm{m} / \mathrm{z}=161$ was formed. With further release of $\mathrm{OH}$, the cation with $\mathrm{m} / \mathrm{z}=144$ was formed. The cation with $\mathrm{m} / \mathrm{z}=144$ can also formed with the release of a methoxyphenyl radical and hydroxyl group from the quasimolecular cation. With destruction of the 1,2,4-triazole-ylthioacetate radical, the methoxyphenyl cation with $\mathrm{m} / \mathrm{z}=107$ was formed. With the release of methoxyphenyl radical and carbon dioxide, the ion with $m / z=130$ was formed. Separation of the $\mathrm{OH}$-group from the quasimolecular ion results in the formation of the cation with $\mathrm{m} / \mathrm{z}=248$ which transforms into the relevant ion with $\mathrm{m} / \mathrm{z}=220$ with CO separation. With further separation of two methylene 


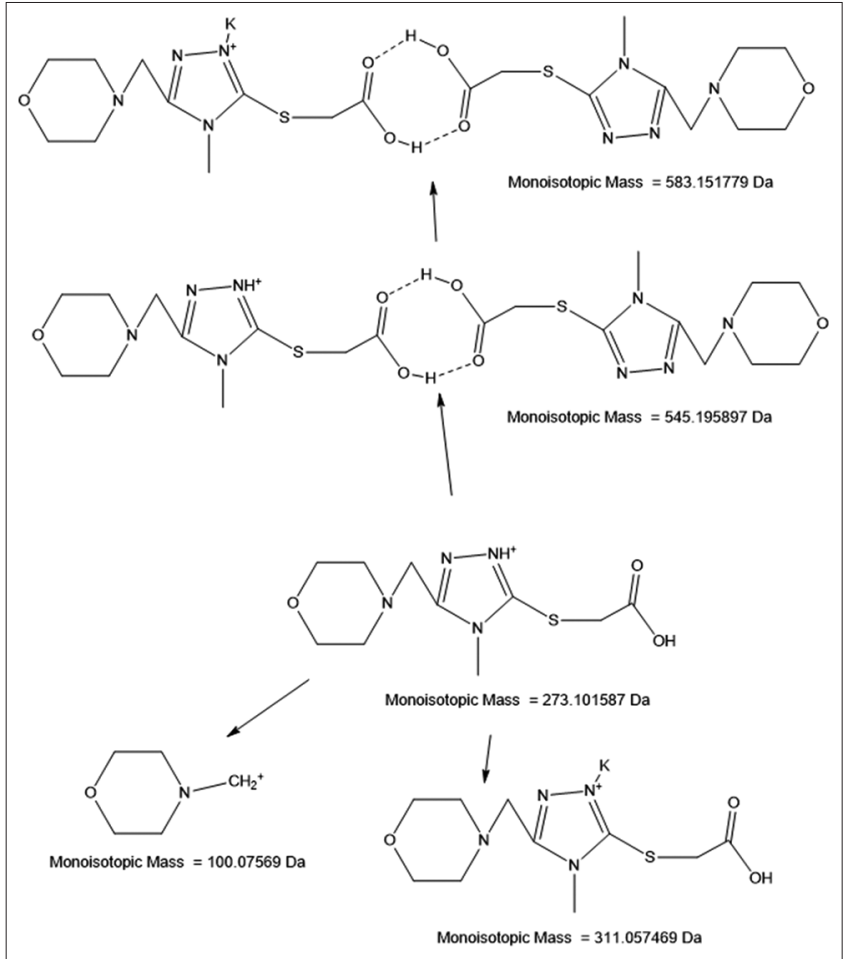

Fig. 16: Proposed fragmentation pattern of the morpholin-4-ium 2-((4-methyl-5-(morpholinomethyl)-4H-1,2,4-triazol-3-yl)thio) acetate abundance at $100 \mathrm{~V}$

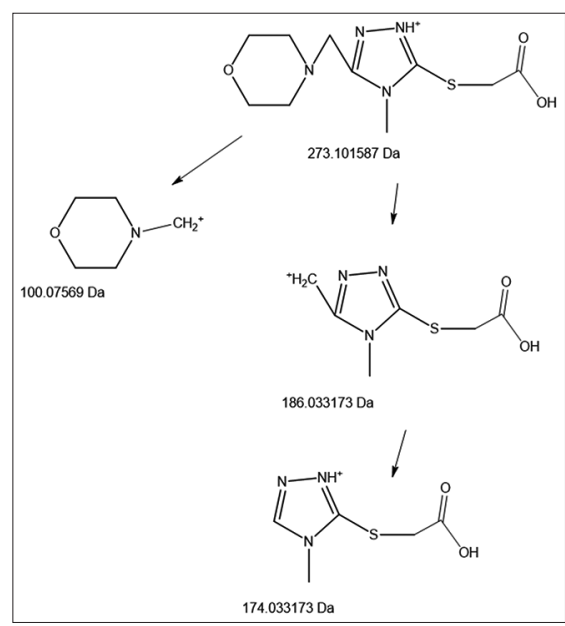

Fig. 17: Proposed fragmentation pattern of the morpholin-4-ium 2-((4-methyl-5-(morpholinomethyl)-4H-1,2,4-triazol-3-yl)thio) acetate abundance at $200 \mathrm{~V}$ groups, the cation with $\mathrm{m} / \mathrm{z}=193$ appears. Further, cyclization and separation of a hydrogen atom results in the formation of the radical cation with $m / z=191$. With separation of one methylene group from the cation with $\mathrm{m} / \mathrm{z}=220$, the radical cation with $\mathrm{m} / \mathrm{z}=207$ appears which transforms into the radical cation with $\mathrm{m} / \mathrm{z}=205$ at cyclization.

During the fragmentation of the quasimolecular ion with partial destruction of the triazole cycle three-membered diazo heterocycles with $\mathrm{m} / \mathrm{z}=151$ and 149 were formed. With the release of one nitrogen atom, it transforms into the radical cation with $\mathrm{m} / \mathrm{z}=133$ having two resonance forms.

A part of the triazole cycle with thioacetate residue from the quasimolecular ion forms the radical cation with a three-membered diazo heterocycle with $\mathrm{m} / \mathrm{z}=132$. Next, with the release of one nitrogen atom new radical cation with $\mathrm{m} / \mathrm{z}=119$ appears. At separation of another nitrogen atom, the cation with $\mathrm{m} / \mathrm{z}=105$ appears. Then, it transforms into the radical cation with $\mathrm{m} / \mathrm{z}=104$ at release of one hydrogen atom. Next, at the release of another hydrogen atom, the cation with $\mathrm{m} / \mathrm{z}=103$ was formed.

\section{CONCLUSIONS}

ESI-MS fragmentation of salts of 1,2,4-triazolylthioacetate acids as active pharmaceutical ingredients of pharmaceutical formulations at different

Table 8: The values of ions $\mathrm{m} / \mathrm{z}$ of zinc

2-((5-(2-methoxyphenyl)-4H-1,2,4-triazol-3-yl) thio) acetate abundance at $100 \mathrm{~V}$ and $200 \mathrm{~V}$

\begin{tabular}{|c|c|c|c|}
\hline \multicolumn{2}{|l|}{$100 \mathrm{~V}$} & \multicolumn{2}{|l|}{$200 \mathrm{~V}$} \\
\hline $\mathbf{m} / \mathbf{z}$ & Abundance & $\mathbf{m} / \mathbf{z}$ & Abundance \\
\hline 157.00 & 0.9 & 101.90 & 1.5 \\
\hline 220.00 & 1.1 & 103.00 & 12.1 \\
\hline 266.00 & 100.0 & 104.10 & 39.2 \\
\hline 277.00 & 1.1 & 117.00 & 1.8 \\
\hline 288.00 & 1.4 & 118.10 & 2.6 \\
\hline \multirow[t]{16}{*}{290.20} & 0.1 & 130.00 & 3.0 \\
\hline & & 132.10 & 18.8 \\
\hline & & 133.10 & 100.0 \\
\hline & & 144.10 & 9.8 \\
\hline & & 149.00 & 1.8 \\
\hline & & 151.00 & 1.0 \\
\hline & & 161.00 & 32.2 \\
\hline & & 177.00 & 6.0 \\
\hline & & 191.00 & 1.8 \\
\hline & & 192.90 & 1.2 \\
\hline & & 205.00 & 8.2 \\
\hline & & 220.10 & 64.7 \\
\hline & & 248.00 & 5.5 \\
\hline & & 266.00 & 11.3 \\
\hline & & 271.00 & 0.3 \\
\hline & & 288.00 & 2.3 \\
\hline
\end{tabular}
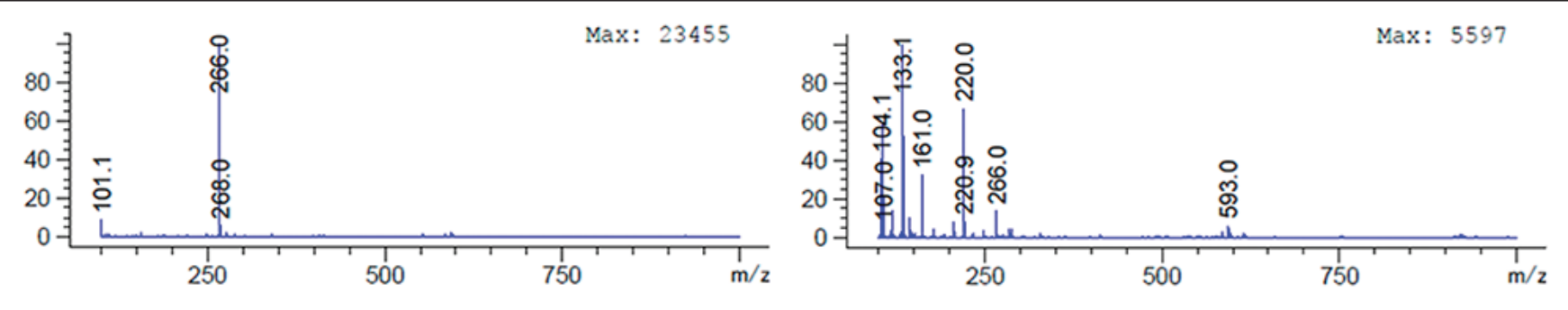

Fig. 18: Mass spectra of zinc 2-((5-(2-methoxyphenyl)-4H-1,2,4-triazol-3-yl)thio) acetate at different fragmentor voltage (100 and $200 \mathrm{~V})$ 


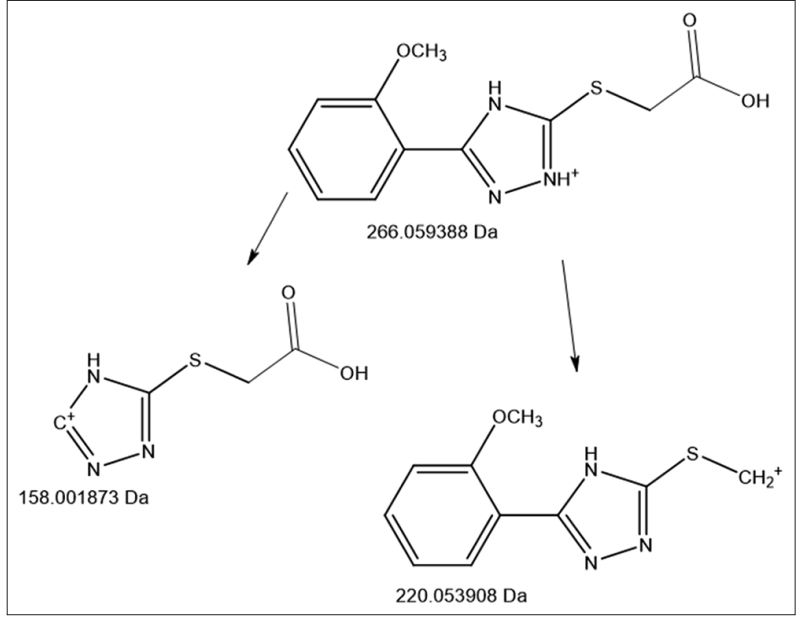

Fig. 19: Proposed fragmentation pattern of the zinc 2-((5-(2-methoxyphenyl)-4H-1,2,4-triazol-3-yl)thio)acetate abundance at $100 \mathrm{~V}$ fragmentor voltage has been studied. The mass spectra of the salt of series 1,2,4-triazolylthioacetate acids have been shown. The fragmentation pathways for the salts of series 1,2,4-triazolylthioacetate acids have been provided. There are several basic regularities, the fragmentation of the investigated derivatives of 1,2,4-triazole: Few studied substances form dimeric cations, some of them creates adducts with sodium and potassium, and the destruction of triazole cycle may lead to the formation of three-membered heterocycles. Studying the fragmentation of the indicated substances can be used for detecting the mentioned substances, as well as for confirming the structure of new compounds with the mass spectrum based on the patterns described above.

\section{ACKNOWLEDGMENTS}

We acknowledge complete support from the Zaporozhye State Medical University. We thank rector of Zaporozhye State Medical University Prof. Yu. M. Kolesnyk for his help and support.

\section{AUTHOR'S CONTRIBUTIONS}

Varynskyi Borys: Elaboration of chromatography and mass spectrometry conditions, data acquisition, data evaluation, interpretation of the

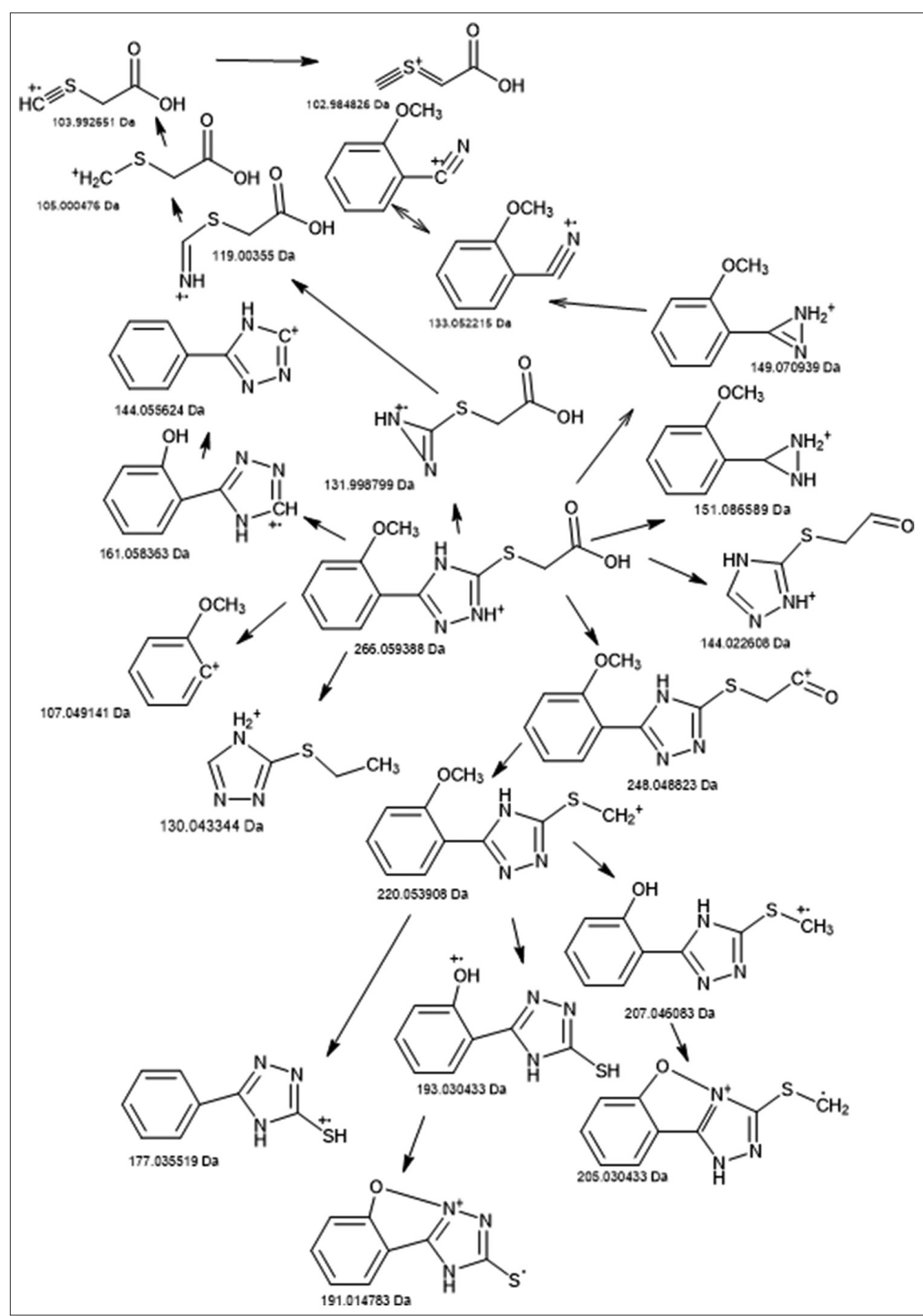

Fig. 20: Proposed fragmentation pattern of the zinc 2-((5-(2-methoxyphenyl)-4H-1,2,4-triazol-3-yl)thio)acetate abundance at $200 \mathrm{~V}$ 
spectra, drafting of report, and approval of the version to be published. Kaplaushenko Andriy: Supervision of the study, revising of report, and approval of the version to be published. Parchenko Vladymyr: Synthesis of some substances and providing of them for the analysis, revising of report, and approval of the version to be published.

\section{CONFLICTS OF INTEREST}

The authors declare that they have no conflicts of interest.

\section{REFERENCES}

1. Varynskyi BO, YeG K, Parchenko VV, Panasenko OI, Kaplaushenko AG. The study of retention regularities for the potential drug substances of 1,2,4-triazol-3-ylthioacetic acids and their salts series by the method of HPLC/DAD-MS. J Org Pharm Chem 2015;13:68-72.

2. Varynskyi BO. Optimization of the detection conditions 1,2,4-triazol3 -yl-thioacetate acids series and their salts by HPLC-ESI-MS. Odessa Med Journ 2015;4:17-21.

3. Philip S, Purohit MN, Krishna KL, Eshwar MS, Raizaday T, Prudhvi S, et al. Design, synthesis and in vitro anti-cancer activity of novel 1,2,4-triazole derivatives. Int J Pharm Pharm Sci 2014;6:185-9.

4. Reddy SK, Purohit MN, Pujar GV. Synthesis and pharmacological activity of some novel bis-heterocycles encompassing pyrrole. Int $\mathrm{J}$
Pharm Pharm Sci 2012;4:153-7.

5. Kaplaushenko TM, Panasenko OI, Kucheryavy Yu. Research of the synthetic, physical and chemical properties of 3-alkylsulfonyl-5(chinoline-2-yl,2-hydroxychinoline-4-yl)-4-R1-2,4-dihydro)3N-1,2,4triazoles. Asian J Pharm Clin Res 2017;10:81-3.

6. Salgın-Gökșen U, Gökhan-Kelekçi N, Göktaş Ö, Köysal Y, Kılıç E, Işık Ş, et al. 1-Acylthiosemicarbazides, 1,2,4-triazole-5(4H)-thiones, 1,3,4thiadiazoles and hydrazones containing 5-methyl-2-benzoxazolinones: Synthesis, analgesic-anti-inflammatory and antimicrobial activities. Bioorg Med Chem 2007; 15:5738-51

7. Küçükgüzel I, Tatar E, Küçükgüzel SG, Rollas S, De Clercq E. Synthesis of some novel thiourea derivatives obtained from 5-[(4-aminophenoxy) methyl]-4-alkyl/aryl-2,4-dihydro-3H-1,2,4-triazole-3-thiones and evaluation as antiviral/anti-HIV and anti-tuberculosis agents. Eur J Med Chem 2008;43:381-92.

8. Gülerman NN, Dogan HN, Rollas S, Johansson C, Celik C. Synthesis and structure elucidation of some new thioether derivatives of 1,2,4-triazoline-3-thiones and their antimicrobial activities. Il Farmaco 2001;56:953-8.

9. Eswaran S, Adhikari AV, Shetty NS. Synthesis and antimicrobial activities of novel quinoline derivatives carrying 1,2,4-triazole moiety. Eur J Med Chem 2009;44:4637-40.

10. Salionov VA, Varynskyi BA, Parchenko VV. Mass-spectrometric fragmentation of sodium 2-(4-methyl-5-(thiophene-2-yl)-4H-1, 2, 4-triazole-3-ylthio) acetate. Zaporož Med Ž 2015;92:93-6. 